\title{
Aza-18-crown-6 modifiye karbon nanotüplerin sentezi, karakterizasyonu ve adsorpsiyon kapasitesinin belirlenmesi
}

\author{
Baki ÇIÇEK* \\ Balıkesir Üniversitesi Fen Edebiyat Fakültesi Kimya Bölümü, Çağış Kampüsü, Balıkesir.
}

Geliş Tarihi (Received Date): 15.05.2021

Kabul Tarihi (Accepted Date): 09.06.2021

$\ddot{\mathbf{O} z}$

Karbon nanotüpler (CNT) olağanüstü eşsiz özellikleri sebebiyle keşfinden günümüze birçok uygulama alanı bulmuştur. Yüzeylerinde gerçekleştirilen kovalent modifikasyonlarla kimyasal ve fiziksel özellikleri geliştirilebilmektedir. Bu çalışma ile 1aza-18-crown-6 modifiye karbon nanotüpler Steglich esterleşmesi ile sentezlenmiştir. Sentezlenen bileşik FTIR, ${ }^{1} \mathrm{H}-\mathrm{NMR},{ }^{13} \mathrm{C}-\mathrm{NMR}$, TGA ve TEM yöntemleriyle karakterize edilmiştir. Elde edilen bileşiğin ve modifiye edilmemiş $\mathrm{CNT}$ bileşiğinin $\mathrm{Fe}^{3+}, \mathrm{Mn}^{2+}, \mathrm{Co}^{2+}$, $\mathrm{Cr}^{3+}, \mathrm{Cu}^{2+}, \mathrm{Zn}^{2+}$ metal iyonlarını adsobsiyonu incelenmiştir. Adsorpsiyon yüzdesi (\% A.Y.), adsorpsiyon kapasitesi $\left(q_{e}\right)$, maksimum adsorpsiyon kapasitesi $\left(q_{\max }\right)$, adsorpsiyon denge sabiti $\left(K_{d}\right)$, Serbest Gibbs Enerjisi $\left(\Delta \mathrm{G}^{\mathrm{o}}\right)$ ve izoterm türü belirlenmiştir. Adsorpsiyon çallşmalarına göre, monoaza-18-crown-6 modifiye edilmiş çok duvarlı karbon nanotüp (MWCNT-CO-(MA-18-Crown-6)) bileşiği, tüm metal iyonlarını ham çok duvarl k karbon nanotüpten (MWCNT) çok daha iyi yüzdelerde adsorbe ettiği gözlenmiştir. MWCNT-CO-(MA-18-Crown-6) bileşiği, çözelti içindeki Fe ${ }^{3+}$ iyonlarının yaklaşık olarak tamamını (\% 96.15) adsorbe etmiştir. Bu sonuçlar ışığında elde edilen MWCNT-CO-(MA-18-Crown-6) bileşiği metal iyonlarının sulu ortamlardan adsorpsiyonunda başarılı bir şekilde uygulanabileceği söylenebilir.

Anahtar kelimeler: MWCNT, modifikasyon, Steglich amit sentezi, karakterizasyon, adsorpsiyon.

\footnotetext{
*Baki ÇIÇEK, bcicek@balikesir.edu.tr, http://orcid.org/0000-0003-1257-1188
} 


\title{
Synthesis and characterization determination aza-18-crown-6 modified carbon nanotubes and determination of adsorption capacity
}

\begin{abstract}
Carbon nanotubes (CNT) have found many applications since their discovery due to their extraordinary unique properties. Its chemical and physical properties can be improved by covalent modifications on its surfaces. In this study, 1-aza-18-crown-6 modified carbon nanotubes were synthesized by Steglich esterification. The synthesized compound was characterized by FTIR, ${ }^{1} H-N M R,{ }^{13} C-N M R$, TGA and TEM methods. The adsorption of $\mathrm{Fe}^{3+}, \mathrm{Mn}^{2+}, \mathrm{Co}^{2+}, \mathrm{Cr}^{3+}, \mathrm{Cu}^{2+}, \mathrm{Zn}^{2+}$ metal ions of the obtained compound and unmodified CNT compound was investigated. Adsorption percentage (A.Y.\%), adsorption capacity $\left(q_{e}\right)$, maximum adsorption capacity $\left(q_{\max }\right)$, adsorption equilibrium constant $\left(K_{d}\right)$, Free Gibbs Energy $\left(\Delta G^{\circ}\right)$ and isotherm type were determined. According to adsorption studies, for the monoaza-18-crown-6 modified multi-walled carbon nanotube (MWCNTCO-(MA-18-Crown-6)) compound has adsorbed all metal ions much better percentages than crude multi-walled carbon nanotube (MWCNT). MWCNT-CO-(MA-18-Crown-6) compound has adsorbed approximately all of the $\mathrm{Fe}^{3+}$ ions in solution (96.15\%). In the light of these results, it can be said that the MWCNT-CO-(MA-18-Crown-6) compound can be successfully applied in the adsorption of metal ions from aqueous environments.
\end{abstract}

Keywords: MWCNT, modification, Steglich amide synthesis, characterization, adsorption.

\section{Giriş}

Karbon materyallerinin fiziksel, kimyasal, mekanik ve elektronik özellikleri sebebiyle (özellikle grafit) günümüzde kullanımı oldukça fazladır. Bu ilgi benzer özelliklere sahip karbon nanotüplere olan ilgiyi de günden güne artmaktadır [1-5]. Bununla beraber karbon materyallerinin yüzeylerinin kimyasal veya fiziksel olarak modifikasyonu ile elde edilen organik formlu ve inorganik formlu yapılar, nanoyapıların farklı alanlardaki kullanım potansiyelini artırmaktadır. Kondensatör, yakıt hücreleri, adsorpsiyon sanayi, her türlü sensör imalatı, her türlü metal-seramik-plastik nano-kompozit materyal imalatı, gaz depolama sanayi, nanoparçalar ve sistemler, vb. nanomateryallerin kullanıldı ğ bazı alanlardan birkaçıdır [6-10]. Karbon nanotüpler üzerindeki modifikasyonlar kovalent ve kovalent olmayan modifikasyonlar olabilir [11]. Kovalent modifikasyonlara oksidasyon (karboksilasyon), amit sentezi, esterleşme, halojenizasyon, katılma reaskiyonları, vb. örnek verilebilir [11-16]. Özellikle karboksilasyon ile karbon nanotüplerin modifikasyonu birçok materyalin sentezlenmesinde öncü olarak kullanılmaktadır. Nitrik asit-sülfürik asit karışımı en fazla kullanılan oksidanlardandır [17]. Amit sentezi de karboksillenmiş karbon nanotüp üzerinden gerçekleştirilmektedir [13]. Elde edilen glikol, tiyol, amit modifiye karbon nanotüpler metal absorbanı olarak oldukça başarılı sonuçlar vermiştir. Amit fonksiyonel grubu içeren ve sterik açıdan gerçekleşmesi pek mümkün olmayan bileşiklerin sentezinde Steglich esterleşmesi sık sık kullanılmaktadır. Çünkü Steglich esterleşmesi aminlerle çok hızlı gerçekleşmektedir. MWCNT-(-CO-NH$\left.\mathrm{CH}_{2} \mathrm{CH}_{2}-\mathrm{NH}_{2}\right)_{n}$ ve MWCNT-(2-aminobenzotiyazol)n bu yöntemle sentezlenen baz1 
nanomateryallerdir [2, 19-20]. 1,12-diaminododekan gibi uzun kuyruklu diaminler ve elektron iletken polimerler olan politiyofen ve poliprol türevi polimerler ile modifiye edilmiş nanomalzemeler, metal iyonlarının yanı sıra bazı küçük organik bileşiklere ve anyonlara ilgi gösterdiği bildirilmiştir [20]. Sanayi ve endüstride meydana gelen tehlikeli kirliliklerin arıtılmasında, klasik arıtma teknolojilerine alternatif olarak adsorpsiyon gibi arıtım teknolojilerinin geliştirilmesi yapılmaktadır [21-22]. Adsorpsiyon yöntemi de ekstraksiyon, potansiyometri, kondüktometri gibi bu ağır toksik materyallerin arıtılmasında önemli bir yere sahiptir [23-27]. Atık sulardan istenmeyen madde gideriminde hatta son yıllarda çözeltiden seçimli olarak uzaklaştırmak istenen maddenin (ağır metal, organik maddeler, boyalar ve toksik elementler, vb.) arıtımında başarılı bir şekilde uygulanmaya başlanmıştır [28-32]. Adsorpsiyon izotermleri bir adsorbanadsorbat arasındaki denge halini göstermek için kullanılan denklemler olup adsorpsiyon izotermleri, adsorpsiyon 1sıs1, adsorpsiyon yoğunluğu, boyutsuz dağılma sabiti, maksimum adsorpsiyon kapasitesi ve gözenek hacminin belirlenmesi amaciyla kullanılırlar. En çok kullanılan izotermler Langmuir ve Freundlich izotermleridir [33-39]. MWCNT-kitosan, 2-aminobenzotiyazol modifiye MWCNT, iminodiasetik asit modifiye MWCNT, etilendiamin modifiye MWCNT, amonyum 1-pirolidin ditiyo-karboksilat modifiye MWCNT, D2EHPA-TOPO s modifiye MWCNT, o-kresolftalyn kompleksi modifiye MWCNT, ÇDKNT-COOH, amino/tiyol modifiye MWCNT bileşikleri biyolojik ve çevre numunelerinden krom, demir, arsenik, vanadyum, kadmiyum, bakır, kobalt, nikel, mangan, çinko, kurşun, cıva adsorpsiyonunda başarılı bir şekilde kullanılmıştır [2, 18-19, 22, 41-45]. Bu çalışmada Steglich amit sentezi ile sentezlenen 1aza-18-crown-6 modifiye MWCNT bileșiği FTIR, NMR, TEM, TGA teknikleriyle karakterize edilmiştir. Elde edilen MWCNT-CO-(MA-18-Crown-6) bileşiği ve MWCNT bileşiğinin $\mathrm{Co}^{2+}, \mathrm{Cr}^{3+}, \mathrm{Cu}^{2+}, \mathrm{Fe}^{3+}, \mathrm{Mn}^{2+}, \mathrm{Zn}^{2+}$ iyonlarını adsorpsiyonunda kullanılmıştır. Frendlick ve Langmuir izotermleri ile adsorbsiyon sabitleri belirlenmiştir.

\section{Deneysel çalışmalar}

\subsection{Kullanilan cihazlar ve kimyasal malzemeler}

Bu çalışmada kullanılan MWCNT (Ürün özellikleri; saflık:\% 92, ortalama çap: 8-10 nm, ortalama uzunluk: 1-3 $\mu$ m, karbon saflığı: \% 92, metal oksit: \% 8, elektriksel iletkenlik: $98 \mathrm{~S} / \mathrm{cm}$, yüzey alanı: $290 \mathrm{~m}^{2} / \mathrm{g}$ ) Sigma Aldrich firmasından temin edildi. Kullanılan kimyasal malzemeler yüksek saflıkta ( $\geq \%$ 97.5) olup ticari olarak (Merck, Sigma Aldrich, Carlo Erba, Roth, vb.) temin edilmiştir. Süzme işlemlerinde, vakumlu cam filtrasyon sistemi (İnterlab) ve $0,45 \mu \mathrm{m}$ naylon süzme kâğıtları kullanılmıştır. Kurutma işleminde Memmert marka etüv kullanılmıştır. FT-IR spektrumu Perkin Elmer BX 2 FTIR Infrared Spektrofotometresi ile kaydedilmiştir. NMR analizleri (Agilent Technologies $400 \mathrm{MHz}$ ) Atatürk Üniversitesi Kimya Bölümü’nde hizmet alımı ile gerçekleştirilmiştir. Termogravimetrik analizler (TGA, Perkin Elmer Pyris 1) Siirt Üniversitesi Laboratuvarlarında gerçekleştirilmiştir. Geçirimli Elektron Mikroskobu (TEM, Hitachi HT7700) ile TEM görüntüleri Atatürk Üniversitesi DAYTAM' da hizmet alımı yöntemiyle gerçekleştirilmiştir (120 KV ve High Resolution). Tuz çözeltilerinde kullanılan ultra saf su, New Human Power I S-UV cihazından elde edilmiş olup iletkenliği $18.3 \mathrm{M} \Omega / \mathrm{cm}$ 'dir. Deneylerde KERN ABJ marka hassas terazi $(\mathrm{d}=0.1 \mathrm{mg})$, Bandolin marka ultrasonik banyo, IKA C-MAG HS-7 marka manyetik karıştırıcı, Hanna HI 2211 model pH metre (HI1131) kullanılmıştır. Son olarak metal adsorbsiyonu çalışmalarında İndüktif Olarak Eşleşmiş Plazma - Optik Emisyon Spektrometresi (ICP-OES, Perkin Elmer Optima 2200 DV) kullanılmıştır. 


\subsection{Sentez}

\subsubsection{Karboksillenmiş MWCNT'lerin sentezi}

MWCNT içerdiği safsızlıklardan kurtulmak amacıyla \% $10 \mathrm{HCl}$ çözeltisi ile yıkandı. Saflaştırılmış MWCNT (1.0 g), 20 mL H2 $\mathrm{SO}_{4}+\mathrm{HNO}_{3}$ karışımına $(3: 1 \mathrm{v} / \mathrm{v})$ ilave edildi. Süspansiyon karışımı 30 dakika ultrasonik banyoya bırakıldı. Geri soğutucu altında 24 saat kaynatıldı. Karboksillenmiş MWCNT santrifüj ile yıkama işlemi ile asidik çözeltiden ayrıldı (30 dakika $5000 \mathrm{rpm}$ ve $15{ }^{\circ} \mathrm{C}$ ). Karboksillenmiş MWCNT $60{ }^{\circ} \mathrm{C}$ 'lik etüvde 24 saat kurutuldu [15].

\subsubsection{1-aza-18-crown-6 modifiye MWCNT sentezi}

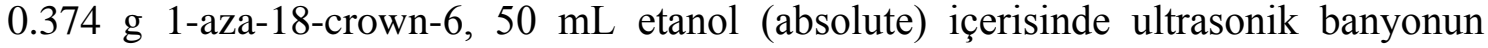
yardımıyla 2 boyunlu reaksiyon balonunda çözündü. $0.5 \mathrm{~g}$ karboksilli asit modifiye MWCNT ilave edildi. Ultrasonik banyoda 30 dakika dispersiye edildi. Geri soğutucu altında kaynatma düzeneğine bağlandı. 45 dakika ısıtılarak ve karıştırılarak iyice dispersiye olması sağlandı. $0.88 \mathrm{~g} \mathrm{~N}, \mathrm{~N}$-disiklohegzilkarbodiimit (DCC) yan koldan reaksiyon balonuna eklenerek 48 saat $78-80{ }^{\circ} \mathrm{C}$ 'de geri soğutucu altında kaynatıldı. Ürün $0.45 \mu \mathrm{m}$ fitre kâğıdından süzüldü. 4 defa etanol ile yıkandı. Etüvde $60{ }^{\circ} \mathrm{C}$ 'de 48 saat kurutuldu. (Verim, $0.375 \mathrm{~g}$ )

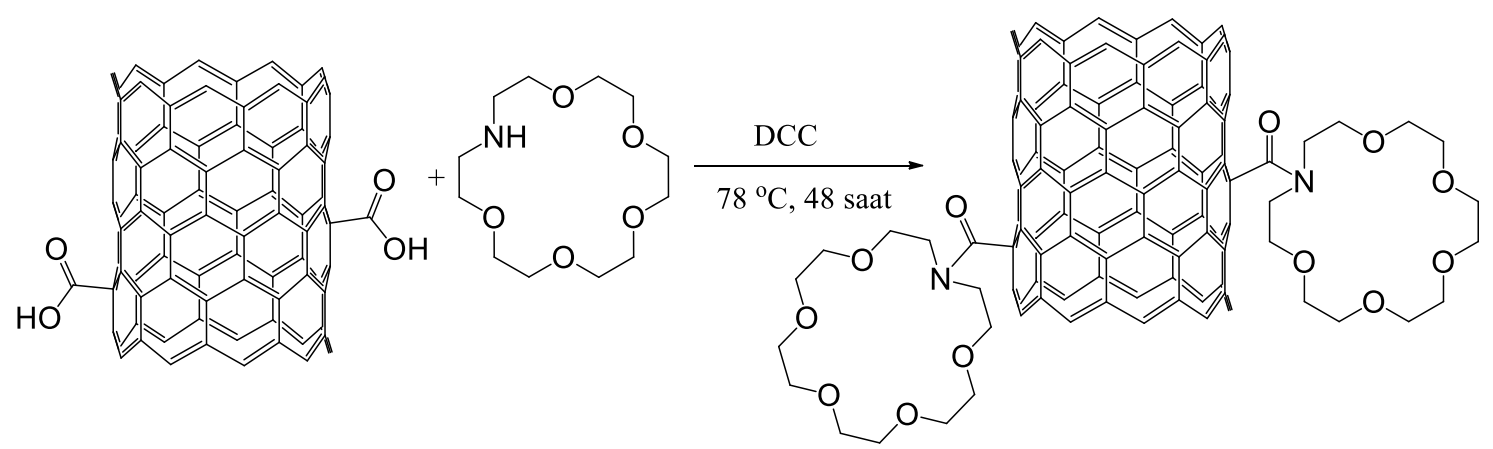

Şekil 1. 1-aza-18-crown-6 modifiye MWCNT bileşiğinin sentezi.

\subsection{Crown eter modifiye MWCNT bileşiğinin adsorpsiyon sabitlerinin belirlenmesi}

\subsubsection{Formülasyon}

Adsorpsiyon için kullanılan bazı formüller aşağıda verilmiştir [46]:

$$
\% A Y=\frac{C_{0}-C_{e}}{C_{0}} \times 100
$$

Burada $\mathrm{C}_{0}$ başlangiç konsantrasyonu ( $\left.\mathrm{mg} / \mathrm{L}\right), \mathrm{C}_{\mathrm{e}}$ ise ilgili prosedür takip edildikten sonra elde edilen dengedeki iyon konsantrasyonu (mg/L) temsil etmektedir.

$$
q_{e}=\left(C_{0}-C_{e}\right) \times \frac{V}{W}
$$

Burada V ilave edilen tuz karışımının hacmini (L), W ise adsorbent madde miktarını (g) temsil etmektedir.

Denge sabiti $K_{c}$ şu şekilde hesaplanabilir; 


$$
K_{c}=\frac{C_{a}}{C_{e}}
$$

Burada $\mathrm{C}_{\mathrm{a}}$ adsorban tarafindan tutulan madde konsantrasyonu $(\mathrm{mg} / \mathrm{L})$ simgelemektedir. $\mathrm{Bu}$ eşitlik (3) kullanılarak hesaplanan $\mathrm{K}_{\mathrm{c}}$ denge sabiti değerlerinin başlangıç tuz konsantrasyonlarına karşı grafiğe geçirilmesiyle oluşan doğrunun kesim noktası $K_{c}^{0}$ değerini verecektir. Elde edilen $K_{c}^{0}$ değeri Eşitlik 4'de yazılırsa adsorbanların serbest Gibbs enerjileri elde edilir.

$$
\Delta G^{0}=R \cdot T \cdot \operatorname{Ln}\left(K_{c}^{0}\right)
$$

Langmuir İzotermi denklemi lineer formu,

$$
\frac{C_{e}}{q_{e}}=\frac{1}{K_{L} \cdot q_{\max }}+\frac{1}{q_{\max }} \cdot C_{e}
$$

şeklindedir. Lineer Langmuir denklemindeki $\mathrm{C}_{\mathrm{e}} / \mathrm{q}_{\mathrm{e}}$ değerleri, $\mathrm{Ce}_{\mathrm{e}}$ değerlerine karşı grafiğe geçirilirse, grafiğin kayım değeri $1 /\left(K_{L} \cdot q_{\max }\right)$, grafiğin eğimi ise $1 / q_{\max }$ olur. $K_{\mathrm{L}}$ ve $\mathrm{q} \max$ değerlerinin belirlenmesi adsorpsiyonun doğasının belirlenmesi için önemlidir. $\mathrm{Bu}$ denklemde; $\mathrm{q}_{\max }$ adsorbentin maksimum adsorplama kapasitesini (mg/g), $\mathrm{K}_{\mathrm{L}}$ adsorpsiyon entalpisine ve sıcaklığa bağl Langmuir izotermi sabitini $(\mathrm{L} / \mathrm{mol})$ ifade etmektedir. Langmuir izoterminin elverişliliğini bulmak için boyutsuz dağılma sabiti $R_{L}$ sabiti şu şekilde hesaplanabilir:

$$
R_{L}=\frac{1}{1+K_{L} \cdot C_{0}}
$$

Freundlich İzotermi denkleminin lineer formu şu şekilde yazılabilir:

$$
\operatorname{Ln} q_{e}=\operatorname{Ln} K_{F}+\frac{1}{n} \cdot \operatorname{Ln} C_{e}
$$

$\mathrm{Bu}$ lineer denklemde $\operatorname{Ln} q_{e}$ değerlerinin $\operatorname{Ln} C_{e}$ değerlerine karşı grafiği çizilirse elde edilen doğrunun denkleminin kayımı $\operatorname{Ln} K_{F}$ değerini, eğimi ise $1 / n$ değerini verir. $\mathrm{n}$ ifadesi birimsiz bir sabit olup adsorpsiyon yoğunluğunun bir ölçüsünü vermektedir. $K_{F}$ deneysel olarak elde edilen Freundlich izotermi sabiti (L/g) olup adsorpsiyon kapasitesine ait bir sabittir.

\subsubsection{Yöntem}

Adsorbsiyon yüzdesi (\%A.Y.), adsorpsiyon kapasitesi ( $\mathrm{q}_{\mathrm{e}}$ ), maksimum adsorbsiyon kapasitesi $\left(\mathrm{q}_{\max }\right)$, adsorbsiyon denge sabiti $\left(\mathrm{K}_{\mathrm{c}}\right)$, adsorpsiyon serbest Gibbs enerjisini $\left(\Delta \mathrm{G}^{\mathrm{o}}\right)$ ve adsorbsiyon türünün belirlenmesi amaciyla $0.5 \times 10^{-4}, 1 \times 10^{-4}, 5 \times 10^{-4}, 10 \times 10^{-4}$ tekli tuz çözeltileri hazırlandı. Bu çözeltilerin pH'ları, doğal pH'ları olup değişkendir.

$10 \mathrm{mg}$ MWCNT türevi $50 \mathrm{~mL}$ 'lik falkon tüpe alındı. Hazırlanan tuz çözeltisinden $20 \mathrm{~mL}$ falkon tüpe ilave edildi. 20 dakika ultrasonik banyoda dispersiye edildi. $300 \mathrm{rpm}$ karıştırma hızında $25^{\circ} \mathrm{C}$ 'de 3 saat çalkalandı. Dinlenmesi için 1 gece bırakıldı. $0.45^{\prime}$ lik şırınga ucu PTFE filtre ile süzülerek ICP-OES'de miktar belirlenmesi yapıldı [46]. 
ICP-OES parametreleri: Source Equiliration Delay (sec):15, Plasma Conditions: Same For All Elements, Plasma Aerosol Type: Wet, Nebuliser Start-up: Instant, Plasma (L/min): 15, Aux (L/min): 0.2, Nebuliser (L/min): 0.80, Power: 1300, View Dist.: 15.0, Plasma View: Axial, Sample Flow Rate (mL/min): 1.50. Dalgaboyları (nm): Co 228.616, Cr 267.716, Cu 327.393, Fe 238.204, Mn 257.610, Zn 206.200. Korelasyon katsay1lar1 $\left(\mathrm{R}^{2}\right)$ : Co 0.999927, Cr 0.998509, Cu 0.997842, Fe 0.998399, Mn 0.999904, Zn 0.999751.

\section{Sonuçlar ve tartışma}

$\mathrm{Bu}$ çalışma kapsamında 1-aza-18-crown-6 modifiye MWCNT bileşiği Steglich esterleşmesi yöntemi kullanılarak gerçekleştirilmiştir. İlk olarak saflaştırılan MWCNT bileşikleri $\mathrm{H}_{2} \mathrm{SO}_{4} / \mathrm{HNO}_{3}$ asit karışımı ile oksidasyona maruz bırakılmıştır. Karboksillenmiş MWCNT bileşikleri Steglich amit sentezi yöntemi ile sentezlenmiştir. Elde edilen 1-aza-18-crown-6 modifiye MWCNT bileşiğinin yapısal karakterizasyonu ${ }^{1} \mathrm{H}-\mathrm{NMR},{ }^{13} \mathrm{C}-\mathrm{NMR}$, FT-IR, TGA ve TEM teknikleri ile gerçekleştirilmiştir. Ayrıca seçilen bazı metal nitrat tuzları ile sentezlenen 1-aza-18-crown-6 modifiye MWCNT bileşiği arasındaki adsorbsiyon türü ve mekanizması belirlenmeye çalışılmıştır. Adsorpsiyon yüzdesi, adsorbsiyon denge sabiti, serbest Gibbs enerjisi, adsorbsiyon türü gibi bazı adsorbsiyon parametreleri belirlenmiştir.

MWCNT'lerin oksidasyonu için $\mathrm{HNO}_{3} / \mathrm{H}_{2} \mathrm{SO}_{4}$ yöntemi kullanılmıştır [15]. Saflaştırılmış MWCNT, hacimce $1 / 3$ oranında $\mathrm{HNO}_{3} / \mathrm{H}_{2} \mathrm{SO}_{4}$ ile oksidasyona maruz birakılarak karboksilli asit modifiye MWCNT bileşiği elde edilmiştir. MWCNT-COOH bileşiği FTIR spektrumu incelendiğinde, karboksilli asit $-\mathrm{C}(\mathrm{O})-\mathrm{OH}$ gerilmesi $\left(3267 \mathrm{~cm}^{-1}\right)$ ve $\mathrm{C}=\mathrm{O}$ karbonil gerilmesi $\left(1631 \mathrm{~cm}^{-1}\right)$ bileşik kontrol edilmiştir. Karboksillenmiş MWCNT bileşiği Steglich esterleşme-amit sentezi reaksiyonu ile 1-aza-18-crown-6 bileşiğinin amin grubu üzerinden disiklohegzilkarbodiimit (DCC) kullanılarak amit oluşturmuştur. Steglich esterleşmesi kullanılarak kısa sürede daha kararlı bileşikler üzerinden ve hacimli reaktantların kullanılmasıyla sterik engel sebebiyle ana ürün olarak eldesi zor olan 1-aza18-crown-6 modifiye MWCNT bileşiği elde edilmiştir.

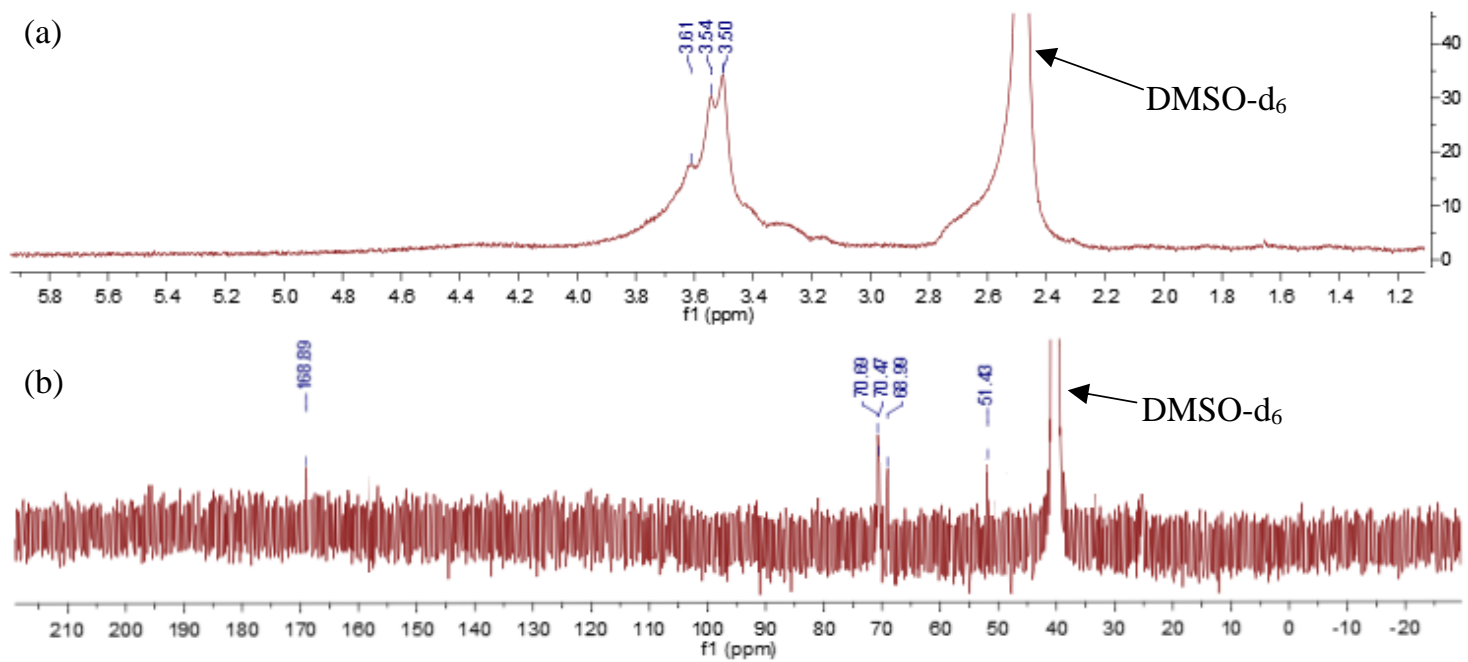

Şekil 2. Sentezlenen 1-aza-18-crown-6 modifiye MWCNT bileşiğinin ${ }^{1} \mathrm{H}-\mathrm{NMR}$ (a) ve ${ }^{13} \mathrm{C}-\mathrm{NMR}(\mathrm{b})$ spektrumu. 
Sentezlenen bileșiğin ${ }^{1} \mathrm{H}-\mathrm{NMR}$ spektrumu Şekil 2(a) incelendiğinde crown eter halkas1 üzerinde yer alan azota bağlı metilen protonları $\left(\mathrm{N}-\underline{C}_{2}-\mathrm{CH}_{2}-\mathrm{O}\right) 3.62 \mathrm{ppm}$ 'de gözlenmiştir. Ayrıca diğer metilen protonları sırasıyla $3.54 \mathrm{ppm}\left(\mathrm{N}-\mathrm{CH}_{2}-\mathrm{CH}_{2}-\mathrm{O}\right)$ ve 3.50 ppm'de (O-C $\left.\underline{\mathbf{H}}_{2}-\underline{\mathbf{H}}_{2}-\mathrm{O}\right)$ gözlenmiştir. ${ }^{13} \mathrm{C}-\mathrm{NMR}$ spektrumu Şekil 2(b)'de 168.9 ppm'de karbonil karbonuna $(-\mathrm{N}-\underline{\mathbf{C}}=\mathrm{O})$ ait kimyasal kayma gözlenmiştir. Bununla beraber 51 ppm'de (CO-N- $\left.\underline{\mathbf{C}} \mathrm{H}_{2}\right), 69$ ppm'de (CO-N-CH $\left.2-\underline{\mathbf{C H}}_{2}\right), 70.3$ ppm'de $\left(\mathrm{O}-\underline{\mathbf{C}} \mathrm{H}_{2}-\mathrm{CH}_{2}-\mathrm{O}\right), 70.6$ ppm'de $\left(\mathrm{O}-\mathrm{CH}_{2}-\underline{\mathbf{C H}}_{2}-\mathrm{O}\right)$ metilen karbonlarına ait kimyasal kaymalar tespit edilmiştir.

Bileşiğin FTIR spektrumunda (Şekil 3(a)) karboksilli aside ait $-\mathrm{C}(\mathrm{O})-\mathrm{OH}$ gerilmesinin $\left(3267 \mathrm{~cm}^{-1}\right)$ kaybolması ve $\mathrm{C}=\mathrm{O}$ karbonil gerilmesi'nin $\left(1631 \mathrm{~cm}^{-1}\right), 1700 \mathrm{~cm}^{-1}$ deki $\mathrm{O}=\mathrm{C}$ $\mathrm{N}$ gerilmesine kayması bileşiğin kovalent modifikasyonla modifiye edildiğini göstermektedir. Ayrıca, Şekil 3(b)'de 2914-2841 cm ${ }^{-1} \mathrm{CH}_{2}$ gruplarının asimetrik ve simetrik gerilmeleri, $1241-1472 \mathrm{~cm}^{-1}$ amite bağl1 metilenin $\left(\mathrm{O}=\mathrm{C}-\mathrm{N}-\mathrm{CH}_{2}\right)$ simetrik ve asimetrik eğilmeleri, 1163 eter eğilmesi, $814 \mathrm{~cm}^{-1}$ eter eğilmesi gözlenmiştir.

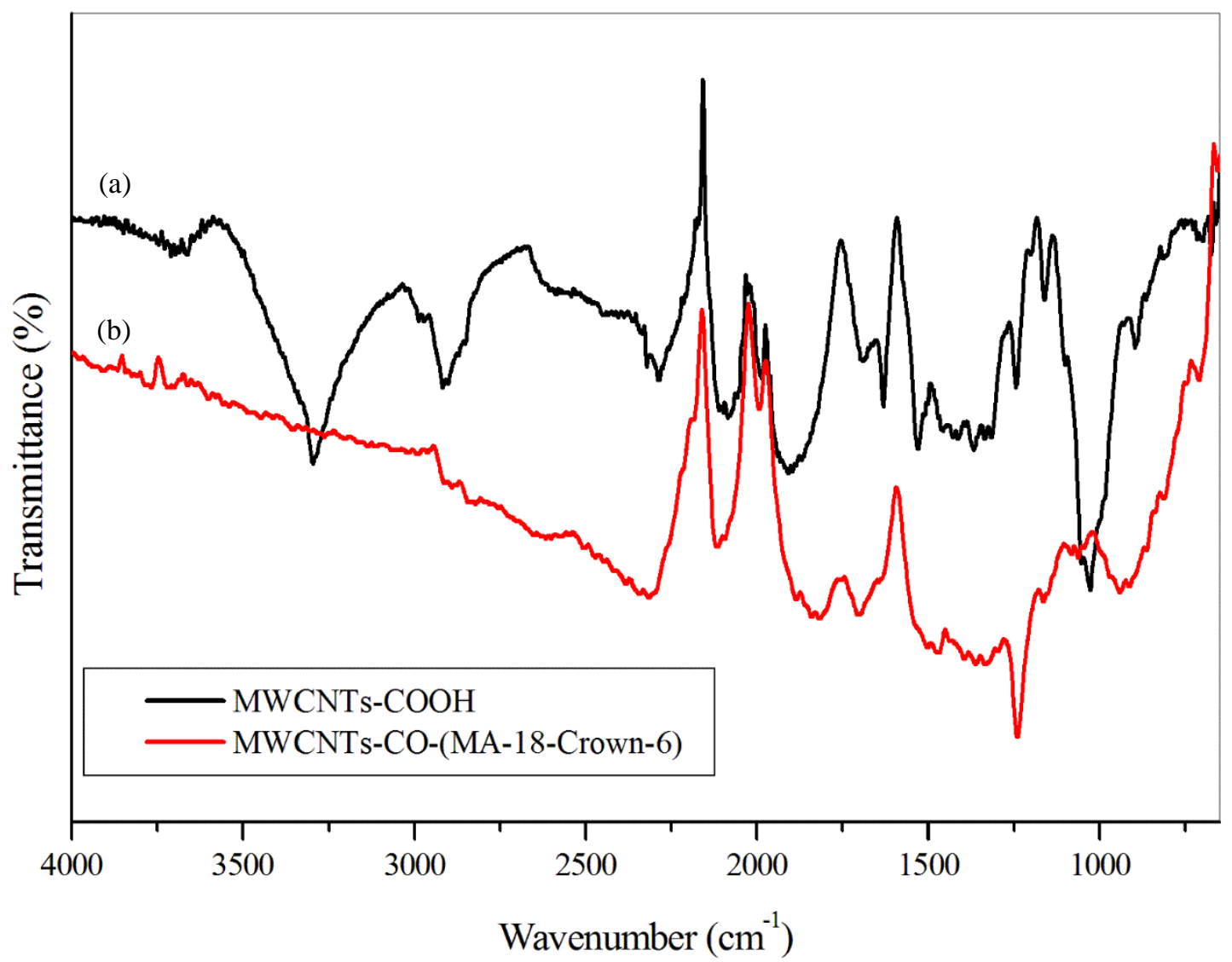

Şekil 3. MWCNT-COOH bileşiğinin (a) ve sentezlenen 1-aza-18-crown-6 modifiye MWCNT bileşiğinin (b) FTIR spektrumu.

TGA spektrumu (Şekil 4) incelendiğinde $572{ }^{\circ} \mathrm{C}^{\prime}$ ye kadar \% 31.8'inin bozunduğu gözlenmiştir. Ancak MWCNT bileşiğinin $595^{\circ} \mathrm{C}^{\circ}$ ye dek sadece \%3.6'sı ve MWCNT$\mathrm{COOH}$ bileşiğinin de $595{ }^{\circ} \mathrm{C}$ 'ye kadar \%22.8'inin bozunduğu literatür verilerinde yer almaktadır [15]. Bununla beraber TEM görüntüsü (Şekil 5) incelendiğinde nanotüp yapısının korunduğu gözlenmiştir. 


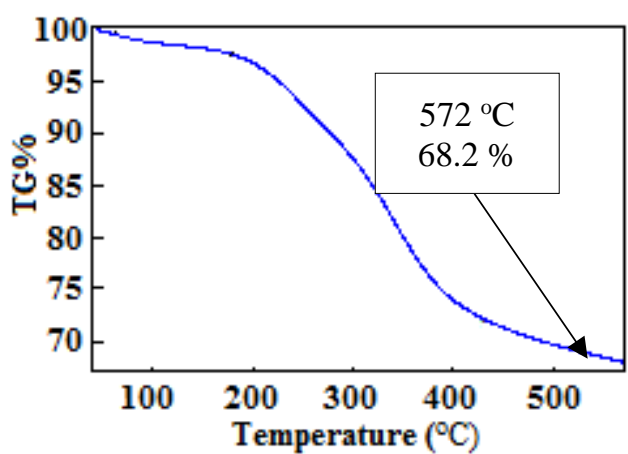

Şekil 4: MWCNT-CO-(MA-18CROWN-6) bileşiğinin termogram değerlendirmesi.

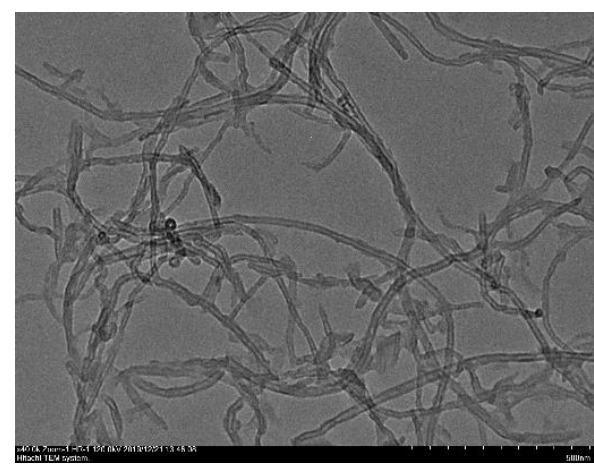

Şekil 5: MWCNT-CO-(MA-18CROWN-6) bileşiğinin TEM görüntüsü (x40.0k Zoom-1 HR-1 $120.0 \mathrm{kV}$ ve 500 $\mathrm{nm})$.

Karakterize edilen MWCNT-CO-(MA-18-Crown-6) bileşiği metal adsorpsiyonu çalışmalarında kullanılmıştır. Bu amaçla farklı konsantrasyonlarda $\left(0.5 \times 10^{-4} \mathrm{M}, 1.0 \times 10^{-4}\right.$ $\left.\mathrm{M}, \quad 5.0 \times 10^{-4} \mathrm{M}, \quad 10.0 \times 10^{-4} \mathrm{M}\right)$ hazirlanan $\mathrm{Fe}\left(\mathrm{NO}_{3}\right)_{3} .9 \mathrm{H}_{2} \mathrm{O}, \quad \mathrm{Mn}\left(\mathrm{NO}_{3}\right)_{2} .4 \mathrm{H}_{2} \mathrm{O}$, $\mathrm{Zn}\left(\mathrm{NO}_{3}\right)_{2} .6 \mathrm{H}_{2} \mathrm{O}, \mathrm{Cu}\left(\mathrm{NO}_{3}\right)_{2} .3 \mathrm{H}_{2} \mathrm{O}, \mathrm{Cr}\left(\mathrm{NO}_{3}\right)_{3} .9 \mathrm{H}_{2} \mathrm{O}, \mathrm{Co}\left(\mathrm{NO}_{3}\right)_{2} .6 \mathrm{H}_{2} \mathrm{O}$ tuz çözeltileri hem MWCNT hem de MWCNT-CO-(MA-18-Crown-6) bileşiğine uygulanmıştır. İşlem sonunda sulu çözeltide kalan tuz konsantrasyonu ICP-OES ile belirlenmiştir (Tablo 1).

Dört farklı konsantrasyonda gerçekleştirilen deneylerde genel olarak konsantrasyon artışının adsorpsiyon yüzdesini azalttığ 1 gözlenmiştir. $\mathrm{Co}^{2+}$ iyonu MWCNT bileşiği tarafından çok az adsorbe edilirken (\% 0.38) MWCNT-CO-(MA-18-Crown-6) bileşiğinin \% 16.33 oranında daha iyi adsorbe ettiği gözlenmiştir. $\mathrm{Cr}^{3+}$ iyonu MWCNT-CO-(MA18-Crown-6) bileşiği, fonksiyonel grup içermeyen MWCNT bileşiğine göre dört kat daha fazla adsorbe ettiği gözlenmiştir $\left(\% 66.24>\%\right.$ 17.54). $\mathrm{Cu}^{2+}$ iyonu da benzer şekilde modifiye edilen MWCNT-CO-(MA-18-Crown-6) bileşiği tarafından yaklaşık 8 kat daha iyi adsorplanmıştır (\% $41.09>\%$ 5.94). Demir (III) iyonunun karbon nanotüp türevleri tarafından çok iyi adsorplandığı bilinmektedir [46]. Ayrıca crown eter türevleri de metal iyonlarına ilgi göstermektedir [47-51]. $\mathrm{Fe}^{3+}$ iyonu, hem MWCNT bileşiği tarafından (\% 84.41) hem de MWCNT-CO-(MA-18-Crown-6) bileşiği tarafından (\% 96.15) yüksek oranlarda adsorbe edilmiştir. $\mathrm{Mn}^{2+}$ iyonu, her iki adsorban tarafından artan konsantrasyonlarla daha iyi yüzdeyle adsorbe edilmiştir. Ancak adsorbanlar arasında adsorbsiyon oranında pek fark olmadığı, çok az bir farkla sentezlenen crown eter modifiye MWCNT bileşiğinin yüksek verimle adsorbsiyon yaptığı olduğu gözlenmiştir (\% $37.42>\%$ 36.11). Son olarak çinko (II) iyonun, sentezlenen MWCNT-CO-(MA-18Crown-6) bileşiği tarafından ham karbon nanotüpe göre yaklaşık altı kat oranla daha iyi adsorbe edildiği tespit edilmiştir. (\% $5.43<\%$ 29.40). Sentezlenen MWCNT-CO-(MA18-Crown-6) adsorbanı için adsorbsiyon yüzdesi büyükten küçüğe sıralanırsa $\mathrm{Fe}^{3+}>\mathrm{Cr}^{3+}$ $>\mathrm{Cu}^{2+}>\mathrm{Mn}^{2+}>\mathrm{Co}^{2+}>\mathrm{Zn}^{2+}>\mathrm{Co}^{2+}$ şeklindedir.

Modifiye olmamış CNT'e göre crown eter modifiye olmuş CNT'lerin yüksek seviyede adsorbe etmesinin iki sebebi vardır. Birincisi modifiye edilmiş MWCNT bileşiğinin yüksek fiziksel adsorbsiyonu; diğer önemli sebep ise crown eter kimyasının temeli olan iyon-dipol etkileşmesiyle kompleksleşme özelliğini sergilemesidir [27]. Bu da literatüre yenilik katmaktadır. 
Eşitlik (3) ve (4) kullanılarak $\Delta \mathrm{G}^{\mathrm{o}}$ değerleri hesaplanmıştır. Serbest Gibbs enerjisinin negatif işaretli olması adsorbsiyonun kendiliğinden (istemli) gerçekleştiğini, pozitif işaretli olması ise adsorpsiyonun gerçekleşmesi için enerjiye ihtiyaç olduğunu göstermektedir. Buna göre Tablo 1 incelendiğinde demir (III) iyonunun her iki adsorban tarafından adsorpsiyonunun istemli olduğu, diğer tuzların enerjiye ihtiyaç duyduğu gözlenmiştir.

Tablo 1. MWCNT ve MWCNT-CO-(MA-18-Crown-6) bileşiklerinin, $25^{\circ} \mathrm{C}^{\prime} \mathrm{de} \mathrm{Co}^{2+}$, $\mathrm{Cr}^{3+}, \mathrm{Cu}^{2+}, \mathrm{Fe}^{3+}, \mathrm{Mn}^{2+}, \mathrm{Zn}^{2+}$ iyonlarını adsorpsiyonu için bulunan veya hesaplanan \% A.Y., $\mathrm{C}_{0}, \mathrm{C}_{\mathrm{e}}, \mathrm{q}_{\mathrm{e}}, \mathrm{C}_{\mathrm{e}} / \mathrm{q}_{\mathrm{e}}, \mathrm{Ln} \mathrm{q}_{\mathrm{e}}, \mathrm{Ln} \mathrm{C}_{\mathrm{e}}$ ve $\Delta \mathrm{G}^{\mathrm{o}}$ değerleri.

\begin{tabular}{|c|c|c|c|c|c|c|c|c|c|}
\hline & & $\begin{array}{c}\mathrm{C}_{0} \\
(\mathrm{mg} / \mathrm{L})\end{array}$ & $\begin{array}{c}\mathrm{Ce} \\
(\mathrm{mg} / \mathrm{L})\end{array}$ & $\begin{array}{l}\text { A.Y. } \\
(\%)\end{array}$ & $\begin{array}{c}\mathbf{q e} \\
(\mathrm{mg} / \mathrm{g})\end{array}$ & $\begin{array}{l}\text { Ce/qe } \\
(\mathrm{g} / \mathrm{L})\end{array}$ & Ln qe & Ln Ce & $\begin{array}{c}\Delta \mathrm{G}^{\mathbf{0}} \\
(\mathrm{kJ} / \mathrm{mol})\end{array}$ \\
\hline \multirow{8}{*}{$\mathrm{Co}^{2+}$} & \multirow{4}{*}{ MWCNT } & 2.99 & 2.98 & 0.38 & 0.02 & 129.57 & -3.772 & 1.092 & \multirow{4}{*}{13742.2} \\
\hline & & 5.98 & 5.96 & 0.38 & 0.05 & 129.57 & -3.079 & 1.785 & \\
\hline & & 29.92 & 29.82 & 0.32 & 0.19 & 156.95 & -1.661 & 3.395 & \\
\hline & & 59.83 & 59.66 & 0.28 & 0.34 & 175.47 & -1.079 & 4.089 & \\
\hline & MWCNT- & 2.99 & 2.50 & 16.33 & 0.98 & 2.56 & -0.023 & 0.917 & \multirow{4}{*}{4246.6} \\
\hline & CO-(MA- & 5.98 & 5.14 & 14.16 & 1.69 & 3.03 & 0.527 & 1.636 & \\
\hline & \multirow{2}{*}{$\begin{array}{c}\text { 18-Crown- } \\
6)\end{array}$} & 29.92 & 28.95 & 3.23 & 1.93 & 15.00 & 0.658 & 3.366 & \\
\hline & & 59.83 & 58.83 & 1.67 & 2.00 & 29.42 & 0.693 & 4.075 & \\
\hline \multirow{8}{*}{$\mathrm{Cr}^{3+}$} & \multirow{4}{*}{ MWCNT } & 2.88 & 2.38 & 17.54 & 1.01 & 2.35 & 0.011 & 0.866 & \multirow{4}{*}{3897.76} \\
\hline & & 5.77 & 4.78 & 17.09 & 1.97 & 2.43 & 0.678 & 1.564 & \\
\hline & & 28.83 & 27.08 & 6.05 & 3.49 & 7.76 & 1.250 & 3.299 & \\
\hline & & 57.65 & 54.47 & 5.52 & 6.36 & 8.56 & 1.850 & 3.998 & \\
\hline & \multirow{4}{*}{$\begin{array}{c}\text { MWCNT- } \\
\text { CO-(MA- } \\
18- \\
\text { CROWN-6) }\end{array}$} & 2.88 & 0.97 & 66.24 & 3.82 & 0.25 & 1.340 & -0.027 & \multirow{4}{*}{-839.61} \\
\hline & & 5.77 & 3.14 & 45.60 & 5.26 & 0.60 & 1.660 & 1.143 & \\
\hline & & 28.83 & 25.13 & 12.82 & 7.39 & 3.40 & 2.000 & 3.224 & \\
\hline & & 57.65 & 53.03 & 8.01 & 9.24 & 5.74 & 2.224 & 3.971 & \\
\hline \multirow{8}{*}{$\mathrm{Cu}^{2+}$} & \multirow{4}{*}{ MWCNT } & 2.928 & 2.75 & 5.94 & 0.35 & 7.91 & -1.056 & 1.013 & \multirow{4}{*}{6928.96} \\
\hline & & 5.856 & 5.54 & 5.40 & 0.63 & 8.77 & -0.459 & 1.712 & \\
\hline & & 29.28 & 28.08 & 4.10 & 2.40 & 11.70 & 0.875 & 3.335 & \\
\hline & & 58.56 & 56.54 & 3.45 & 4.04 & 14.00 & 1.396 & 4.035 & \\
\hline & \multirow{4}{*}{$\begin{array}{c}\text { MWCNT- } \\
\text { CO-(MA- } \\
\text { 18-Crown- } \\
6 \text { ) }\end{array}$} & 2.928 & 1.73 & 41.09 & 2.41 & 0.72 & 0.878 & 0.545 & \multirow{4}{*}{1356.21} \\
\hline & & 5.856 & 3.99 & 31.88 & 3.73 & 1.07 & 1.317 & 1.384 & \\
\hline & & 29.28 & 26.87 & 8.23 & 4.82 & 5.57 & 1.573 & 3.291 & \\
\hline & & 58.56 & 54.42 & 7.07 & 8.28 & 6.57 & 2.114 & 3.997 & \\
\hline \multirow{8}{*}{$\mathrm{Fe}^{3+}$} & \multirow{4}{*}{ MWCNT } & 3.04 & 1.30 & 57.10 & 3.47 & 0.38 & 1.244 & 0.265 & \multirow{4}{*}{-1850.09} \\
\hline & & 6.08 & 2.17 & 64.26 & 7.81 & 0.28 & 2.055 & 0.775 & \\
\hline & & 30.38 & 4.74 & 84.41 & 51.28 & 0.09 & 3.937 & 1.555 & \\
\hline & & 60.75 & 16.94 & 72.12 & 87.62 & 0.19 & 4.473 & 2.830 & \\
\hline & \multirow{4}{*}{$\begin{array}{c}\text { MWCNT- } \\
\text { CO-(MA- } \\
\text { 18-Crown- } \\
6) \\
\end{array}$} & 3.04 & 0.12 & 96.15 & 5.84 & 0.02 & 1.765 & -2.146 & \multirow{4}{*}{-7133.82} \\
\hline & & 6.08 & 0.53 & 91.28 & 11.09 & 0.05 & 2.406 & -0.635 & \\
\hline & & 30.38 & 8.12 & 73.27 & 44.51 & 0.18 & 3.796 & 2.094 & \\
\hline & & 60.75 & 21.65 & 64.36 & 78.20 & 0.28 & 4.359 & 3.075 & \\
\hline \multirow{8}{*}{$\mathrm{Mn}^{2+}$} & \multirow{4}{*}{ MWCNT } & 1.91 & 1.88 & 1.54 & 0.06 & 31.86 & -2.830 & 0.631 & \multirow{4}{*}{3755.86} \\
\hline & & 3.82 & 2.68 & 29.96 & 2.29 & 1.17 & 0.828 & 0.984 & \\
\hline & & 19.10 & 12.29 & 35.64 & 13.61 & 0.90 & 2.611 & 2.509 & \\
\hline & & 38.19 & 24.40 & 36.11 & 27.58 & 0.88 & 3.317 & 3.195 & \\
\hline & & 1.91 & 1.58 & 17.05 & 0.65 & 2.43 & -0.429 & 0.460 & \multirow{4}{*}{4387.27} \\
\hline & CO-(MA- & 3.82 & 3.33 & 12.86 & 0.98 & 3.39 & -0.018 & 1.202 & \\
\hline & 18-Crown- & 19.10 & 12.64 & 33.80 & 12.91 & 0.98 & 2.558 & 2.537 & \\
\hline & 6) & 38.19 & 23.90 & 37.42 & 28.58 & 0.84 & 3.353 & 3.174 & \\
\hline
\end{tabular}


ÇIÇEK B.

Tablo 1. (Devam1).

\begin{tabular}{cccccccccc}
\hline & 3.07 & 2.98 & 2.97 & 0.18 & 16.36 & -1.704 & 1.091 & \\
\multirow{4}{*}{$\mathrm{Zn}^{2+}$} & 6.14 & 6.12 & 0.26 & 0.03 & 191.25 & -3.442 & 1.812 & 11511.68 \\
\cline { 3 - 9 } & & 30.68 & 30.29 & 1.27 & 0.78 & 38.83 & -0.248 & 3.411 & \\
\cline { 2 - 9 } & 61.36 & 58.03 & 5.43 & 6.66 & 8.71 & 1.896 & 4.061 & \\
MWCNT- & 3.07 & 2.17 & 29.40 & 1.80 & 1.20 & 0.590 & 0.773 & \\
CO-(MA- & 6.14 & 5.03 & 17.96 & 2.20 & 2.28 & 0.790 & 1.616 & 2845.94 \\
18-Crown- & 30.68 & 28.36 & 7.56 & 4.64 & 6.11 & 1.535 & 3.345 & \\
6) & 61.36 & 57.02 & 7.07 & 8.68 & 6.57 & 2.161 & 4.043 & \\
\hline
\end{tabular}

$\mathrm{Co}^{2+}, \mathrm{Cr}^{3+}, \mathrm{Cu}^{2+}, \mathrm{Fe}^{3+}, \mathrm{Mn}^{2+}, \mathrm{Zn}^{2+}$ iyonları için Tablo 1'de yer alan $\mathrm{C}_{0}, \mathrm{Ce}, \mathrm{qe}_{\mathrm{e}}, \mathrm{Ce} / \mathrm{q}_{\mathrm{e}}, \mathrm{Ln}$ $\mathrm{q}_{\mathrm{e}}$, Ln $\mathrm{C}_{\mathrm{e}}$ değerleri kullanılarak adsorpsiyon türü belirlenmeye çalışılmıştır. Adsorpsiyonların Langmuir izotermine ya da Frendlich izotermine göre gerçekleştiği Eşitlik (5), (6) ve (7) kullanılarak elde edilen adsorpsiyon sabitlerine göre belirlenmiştir (Tablo 2).

İlk olarak adsorbsiyonun hangi izoterme göre gerçekleştiğinin belirlenmesi amaciyla Langmuir ve Freundlich izoterm grafiklerinin korelasyon sabitleri $\left(\mathrm{R}^{2}\right.$ değerleri) incelenmiştir. Adsorpsiyon, daha yüksek korelasyon sabitine sahip olan izoterme göre gerçekleşmektedir (eğer izotermlerin her ikisi de 0.95 üzeri korelasyon sabitine sahipse adsorbsiyon her iki izoterme göre gerçekleşebilir). MWCNT bileşiğinin $\mathrm{R}^{2}$ değerleri incelendiğinde kobalt, krom (III), bakır, demir, mangan (II) ve çinko iyonları için adsorbsiyonunun Frendlick izotermine (Tablo 1) göre gerçekleştiği söylenebilir. Sentezlenen MWCNT-CO-(MA-18-Crown-6) bileşiğinin seçilen metal iyonlarını adsorpsiyonları incelendiğinde; kobalt, krom (III), demir (III) iyonları için adsorbsiyonunun büyük oranda Langmuir izotermine (Tablo 1); bakır, mangan (II), çinko iyonları için adsorbsiyonunun Frendlick izotermine (Tablo 1) göre gerçekleşmektedir. Bu sonuçlara göre MWCNT bileşiğinin $\mathrm{Co}^{2+}, \mathrm{Cr}^{3+}, \mathrm{Cu}^{2+}, \mathrm{Fe}^{3+}, \mathrm{Mn}^{2+}, \mathrm{Zn}^{2+}$ iyonlarını adsopsiyonu Frendlick izotermine göre, sentezlenen MWCNT-CO-(MA-18-Crown-6) bileşiğinin uygulanan metal iyonlarını adsopsiyonu Frendlick ya da Langmuir izotermine göre gerçekleşmektedir.

Langmuir izotermine ait sabitlerden olan $\mathrm{q}_{\max }$ değerlerinin pozitif olması çizilen Langmuir izoterminin uygun olduğunu göstermektedir. Adsorbentin $\mathrm{q}_{\max }$ değerinin artması, adsorpsiyonun artması demektir. Ayrıca $\mathrm{q}_{\max }$ değerlerinin pozitif olması adsorban-metal iyonu kompleksleri için Langmuir izoterminin uygunluğunu göstermektedir. Modifiye edilen MWCNT-CO-(MA-18-Crown-6) bileşiğinin $\mathrm{Fe}^{3+}$ iyonuyla adsorpsiyonuna ait qmax değerinin diğer iyonlara göre yaklaşık 8-10 kat büyük olması adsorbsiyonunun Langmuir izotermine göre gerçekleştiğini (86.89) ve $\mathrm{Fe}^{3+}$ iyonunun adsorbsiyonu için oldukça iyi bir adsorban olduğunu göstermektedir.

Ayrıca Langmuir izotermine göre adsorbsiyonu gerçekleşen iyonların elverişliliğinin belirlenmesi amacıyla boyutsuz dağılma sabiti $\left(\mathrm{R}_{\mathrm{L}}\right)$ hesaplanmıştır. MWCNT-CO-(MA18-Crown-6) bileşiğinin $\mathrm{Co}^{2+}, \mathrm{Cr}^{3+}$ ve $\mathrm{Fe}^{3+}$ iyonlarıyla, Langmuir izotermine göre gerçekleşen adsorbsiyonu için boyutsuz dağılma sabiti değerleri incelendiğinde $\mathrm{R}_{\mathrm{L}}$ değerinin $0<\mathrm{R}_{\mathrm{L}}<1$ olması (sırasıyla $0.0004,0.0006,0.0008$ ) adsorpsiyonun elverişli olduğunu göstermektedir.

Buna bağlı olarak, Langmuir izotermi kullanılarak hesaplanan $K_{L}$ sabitinin büyüklüğü, adsorbanın ne kadar iyi bir adsorban olduğunun da göstergesidir. MWCNT-CO-(MA-18- 
Crown-6) bileşiğinin, Langmuir izotermine elverişli olan $\mathrm{Co}^{2+}, \mathrm{Cr}^{3+} \mathrm{ve}^{\mathrm{Fe}^{3+}}$ iyonlarıyla adsorpsiyonu için Tablo 2'de verilen $\mathrm{K}_{\mathrm{L}}$ değerleri incelendiğinde iyi bir adsorban olduğu söylenebilir.

Bununla beraber Freundlich izoterminin elverişli olduğu izotermlerden elde edilen adsorpsiyon yoğunluğu değerinin (n), -bu değer adsorban yüzeylerindeki bağlanmaların gerçekleşebileceği aktif yerlerin bir ölçüsüdür-, birden büyük ise (n>1) adsorpsiyonun elverişli olduğunu ve fiziksel adsorbsiyon olduğunu, birden küçük ise $(n<1)$ adsorpsiyonun kimyasal olduğunu göstermektedir [46]. Tablo 2 incelendiğinde MWCNT bileşiğinin demir (III), mangan (II), çinko iyonlarına ve MWCNT-CO-(MA-18-Crown6) bileşiğinin mangan (II) iyonuna karşı Freundlich izotermine göre iyi birer adsorban oldukları gözlenmektedir. Adsorbsiyonları ise ise Freundlich izotermine göre fizikseldir. Ayrıca Freundlich izotermi kullanılarak hesaplanan adsorpsiyon kapasitesi $\left(\mathrm{K}_{\mathrm{F}}\right)$ sabitinin büyük olması istenilen bir durumdur. Korelasyon sabitine $\left(\mathrm{R}^{2}\right)$ göre MWCNT bileşiğinin tüm adsorpsiyonları Frendlick izotermine göre gerçekleşmekte olduğu belirlenmişti. Aynı zamanda $\mathrm{K}_{\mathrm{F}}$ değerlerinin de oldukça büyük olması bu durumu desteklemektedir. MWCNT-CO-(MA-18-Crown-6) bileşiğinin Langmuir izotermine göre gerçekleşen $\mathrm{Cr}^{3+}$ ve $\mathrm{Fe}^{3+}$ iyonlarını adsorbsiyonu için bu değer oldukça düşüktür.

Tablo 2. MWCNT ve MWCNT-CO-(MA-18-Crown-6) bileşiklerinin $25{ }^{\circ} \mathrm{C}^{\prime} \mathrm{de} \mathrm{Co}^{2+}$, $\mathrm{Cr}^{3+}, \mathrm{Cu}^{2+}, \mathrm{Fe}^{3+}, \mathrm{Mn}^{2+}, \mathrm{Zn}^{2+}$ iyonlarını adsopsiyonu için Langmuir ve Freundlich izotermleri sabitleri.

\begin{tabular}{cccccccccc}
\hline & & \multicolumn{4}{c}{ Langmuir İzotermi } & \multicolumn{3}{c}{ Frendlick İzotermi } & İzoterm \\
\cline { 3 - 8 } & & $\mathrm{q}_{\max }$ & $\mathrm{K}_{\mathrm{L}}$ & $\mathrm{R}^{2}$ & $\mathrm{R}_{\mathrm{L}}$ & $\mathrm{n}$ & $\mathrm{K}_{\mathrm{F}}$ & $\mathrm{R}^{2}$ & Türü \\
\hline \multirow{4}{*}{ MWCNT } & $\mathrm{Co}^{2+}$ & 1.1823 & 0.0067 & 0.9786 & 0.0292 & 0.8955 & 194.6517 & 0.9993 & Frendlick \\
& $\mathrm{Cr}^{3+}$ & 7.7995 & 0.0527 & 0.8604 & 0.0038 & 0.5497 & 2.0321 & 0.9583 & Frendlick \\
& $\mathrm{Cu}^{2+}$ & 9.0603 & 0.0137 & 0.9745 & 0.0143 & 0.8141 & 9.9012 & 0.9996 & Frendlick \\
& $\mathrm{Fe}^{3+}$ & -143.2848 & -0.0250 & 0.1757 & -0.0081 & 1.4523 & 0.5169 & 0.8879 & Frendlick \\
& $\mathrm{Mn}^{2+}$ & -1.2600 & -0.0470 & 0.2922 & -0.0043 & 2.5202 & 4.2256 & 0.7973 & Frendlick \\
& $\mathrm{Zn}^{2+}$ & -0.5912 & -0.0161 & 0.2530 & -0.0126 & 1.9599 & 20.9408 & 0.7022 & Frendlick \\
\hline \multirow{3}{*}{ MWCNT- } & $\mathrm{Co}^{2+}$ & 2.0684 & 0.4988 & 0.9993 & 0.0004 & 0.2662 & 2.1322 & 0.7219 & Langmuir \\
CO-(MA- & $\mathrm{Cr}^{3+}$ & 9.4532 & 0.3285 & 0.9877 & 0.0006 & 0.2115 & 0.0016 & 0.9875 & Langmuir \\
18- & $\mathrm{Cu}^{2+}$ & 8.6223 & 0.1208 & 0.8885 & 0.0017 & 0.3367 & 0.1268 & 0.9060 & Frendlick \\
Crown-6) & $\mathrm{Fe}^{3+}$ & 86.8907 & 0.2600 & 0.9320 & 0.0008 & 0.4992 & 0.0038 & 0.9979 & Langmuir \\
& $\mathrm{Mn}^{2+}$ & -9.9516 & -0.0341 & 0.7099 & -0.0059 & 1.5359 & 2.5976 & 0.9734 & Frendlick \\
& $\mathrm{Zn}^{2+}$ & 10.3426 & 0.0536 & 0.8318 & 0.0037 & 0.4869 & 0.8502 & 0.9590 & Frendlick \\
\hline
\end{tabular}

Sonuç olarak bu çalışmada Steglich esterleşmesi / amit sentezi hacimli ve sterik açıdan pek mümkün olmayan amitlerin sentezinde başarıyla uygulanmıştır. MWCNT-CO-(MA18-Crown-6) bileşiği; MWCNT bileşiğinin karboksilasyonu ve karboksillenmiş MWCNT-COOH bileşiğinin 1-aza-18-crown-6 bileşiğiyle Steglich amit sentezi reaksiyonu üzerinden başarılı bir şekilde sentezlenmiştir. Yapısal karakterizasyonları, FTIR, NMR, TGA ve TEM teknikleri kullanılarak başarılı bir şekilde yapılmıştır. Modifiye edilmiş MWCNT-CO-(MA-18-Crown-6) bileşiğinin adsorbsiyon çalışmaları sonucunda ilginç bulgular elde edilmiştir. Adsorpsiyon sonuçları incelendiğinde, uygulanan tüm iyonların MWCNT-CO-(MA-18-Crown-6) bileşiği tarafından MWCNT bileşiğine göre daha fazla adsorbe edildiği tespit edilmiştir. $\mathrm{Bu}$ durum yüzey modifikasyonuyla moleküle kovalent olarak bağlanan 1-aza-18-crown-6 grubunun metal iyonlarına olan ilgisiyle açıklanabilir. Crown eter modifiye MWCNT bileşiğinin yüksek seviyede adsorbsiyon göstermesinin sebebi crown eterle metal iyonları arasındaki kuvvetli iyon-dipol etkileşmesine dayanan kompleksleşme sonucunda olduğu gözlenmektedir. Elde edilen crown eter modifiye MWCNT bileşiği $\mathrm{Co}^{2+}, \mathrm{Cr}^{3+}, \mathrm{Cu}^{2+}, \mathrm{Fe}^{3+}$, 
$\mathrm{Mn}^{2+}, \mathrm{Zn}^{2+}$ iyonlarının sulu ortamlardan adsorpsiyonu için başarılı bir şekilde uygulanmıştır.

\section{Teșekkür}

$\mathrm{Bu}$ çalışma Balıkesir Üniversitesi BAP birimi tarafindan BAP:2019/066 ve BAP:2020/053 numaralı projelerle desteklenmiştir.

\section{Kaynaklar}

[1] Hong, C. Y., You, Y. Z. ve Pan, C. Y., Synthesis of water-soluble multiwalled carbon nanotubes with grafted temperature-responsive shells by surface RAFT polymerization, Chemistry of Materials, 17, 9, 2247-2254, (2005).

[2] Hadavifar, M., Bahramifar, N., Younesi, H. ve Li, Q., Adsorption of mercury ions from synthetic and real wastewater aqueous solution by functionalized multiwalled carbon nanotube with both amino and thiolated groups, Chemical Engineering Journal, 237, 217-228, (2014).

[3] Mormann, W., Lu, Y., Zou, X. ve Berger, R., Modification and grafting of multiwalled carbon nanotubes with bisphenol-A- polycarbonate, Macromolecular Chemistry and Physics, 209, 2113-2121, (2008).

[4] Li, Z., et al., Chemically-modified activated carbon with ethylenediamine for selective solid-phase extraction and preconcentration of metal ions, Analytica Chimica Acta, 632, 2, 272-277, (2009).

[5] Wang, Y., Iqbal, Z. ve Malhotra, S. V., Functionalization of carbon nanotubes with amines and enzymes, Chemical Physics Letters, 402, 96-101, (2005).

[6] Jiang, G., Wang, L., Chen, C., Dong, X., Chen, T. ve Yu, H., Study on attachment of highly branched molecules onto multiwalled carbon nanotubes, Materials Letters, 59, 2085-2089, (2005).

[7] Wu, T. ve Yuan, Y. J., Alkynylation of carbon nanotube by a peptide bond, Materials Letters, 133, 64-66, (2014).

[8] Profumo, A., et al., Multiwalled carbon nanotube chemically modified gold electrode for inorganic as speciation and $\mathrm{Bi}(\mathrm{III})$ determination, Analytical Chemistry, 78, 12, 4194-4199, (2006).

[9] Lim, J. K., et al., Selective thiolation of single-walled carbon nanotubes, Synthetic Metals, 139, 2, 521-527, (2003).

[10] Lin, Y., Zhou, B., Fernando, K. A. S., Liu, P., Allard, L. F. ve Sun, Y. P., Polymeric carbon nanocomposites from carbon nanotubes functionalized with matrix polymer, Macromolecules, 36, 19, 7199-7204, (2003).

[11] Karousis, N., Tagmatarchis, N. ve Tasis, D., Current progress on the chemical modification of carbon nanotubes, Chemical Reviews, 110, 9, 5366-5397, (2010).

[12] Kim, S. W., et al., Surface modifications for the effective dispersion of carbon nanotubes in solvents and polymers, Carbon N. Y., 501, 3-33, (2012).

[13] Xing, L. ve Imae, T., Size-controlled in situ synthesis of metal nanoparticles on dendrimer-modified carbon nanotubes, The Journal of Physical Chemistry C, 111, 6, 2416-2420, (2007).

[14] Zeynalov, E., et al., The peculiar behavior of functionalized carbon nanotubes in hydrocarbons and polymeric oxidation environments, Journal of Adhesion Science and Technology, 31, 9, 988-1006, (2017).

[15] Çalışır, Ü., Çiçek, B., Synthesis of thiol-glycol-functionalized carbon nanotubes and characterization with FTIR, TEM, TGA, and NMR technics, Chemical 
Papers, 74, 10, 3293-3302, (2020).

[16] Çalışır, Ü., Çiçek, B., Doğan, M., Microwave-assisted cross-coupling synthesis of aryl functionalized MWCNTs and investigation of hydrogen storage properties, Chemical Papers, 1-8, (2021).

[17] Xue, W. and Li, P., dielectrophoretic deposition and alignment of carbon nanotubes in Yellampalli, D. S., Carbon nanotubes - synthesis, characterization, applications, Intech, 171-190, London, (2011).

[18] Li, R., et al., Multiwalled carbon nanotubes modified with 2-aminobenzothiazole modified for uniquely selective solid-phase extraction and determination of $\mathrm{Pb}$ (II) ion in water samples, Microchimica Acta, 172, 3-4, 269-276, (2011).

[19] Zang, Z., Hu, Z., Li, Z., He, Q. and Chang, X., Synthesis, characterization and application of ethylenediamine-modified multiwalled carbon nanotubes for selective solid-phase extraction and preconcentration of metal ions, Journal of Hazardous Materials, 172, 2-3, 958-963, (2009).

[20] Santhosh, P., Manesh, K. M., Gopalan, A. ve Lee, K. P., Novel amperometric carbon monoxide sensor based on multi-wall carbon nanotubes grafted with polydiphenylamine-Fabrication and performance, Sensors \& Actuators, B: Chemical, 125, 1, 92-99, (2007).

[21] Kumar, S., Upadhyay, S. N. ve Upadhya, Y. D., Removal of copper by adsorption on fly ash, Journal of Chemical Technology \& Biotechnology, 37, 4, 281-290, (1987).

[22] Dai, B., et al., Schiff base-chitosan grafted multiwal led carbon nanotubes as a novel solid-phase extraction adsorbent for determination of heavy metal by ICPMS, Journal of Hazardous Materials, 219-220, 103-110, (2012).

[23] Erk, Ç., Cakir, U., Cicek, B., Estimation of $\mathrm{Li}^{+}, \mathrm{K}^{+}$and $\mathrm{Ca}^{2+}$ complexation with 12 crown-4, 15 crown-5 and 18 crown- 6 using a Na ${ }^{+}$ISE in dioxane-water, part IV Cation equilibrium constants of macrocyclic ethers with ion selective electrodes, Mikrochimica Acta, 132, 79-82, (1999).

[24] Çalışır, Ü., Çiçek, B., Taç eterlerin metal iyonları ile kompleksleşmesinin kondüktometriye Job's Plot yönteminin uygulanması ile belirlenmesi, Balıkesir Üniversitesi Fen Bilimleri Enstitüsü Dergisi, 21, 2, 840-854, (2019).

[25] Çiçek, B., Çakir, Ü., Azizoglu, A., The associations of macrocyclic ethers with cations in 1,4-dioxane/ water mixtures; Potentiometric $\mathrm{Na}^{+}$and $\mathrm{K}^{+}$binding measurements and computational study, Journal of Inclusion Phenomena and Macrocyclic Chemistry, 72,121-125, (2012).

[26] Calisir, U., Çiçek, B., Comparison of classic and microwave-assisted synthesis of benzo-thio crown ethers, and investigation of their ion pair extractions, Journal of Molecular Structure, 1148, 505-511, (2017).

[27] Çiçek, B., Çakır, Ü., Erk, Ç., The determination of crown-cation complexation behavior in dioxane/water mixtures by conductometric studies, Polymers for Advanced Technologies, 836, 831-836, (1998).

[28] Çiçek, B. ve Çalışır, Ü., Bazı karbazol schiff bazlarının katyon bağlama özelliklerinin kondüktometrik incelenmesi, Balıkesir Üniversitesi Fen Bilimleri Enstitüsü Dergisi, 19, 2, 246-256, (2017).

[29] Czikkely, M., Neubauer, E., Fekete, I., Ymeri, P. ve Fogarassy, C., Review of heavy metal adsorption processes by several organic matters from wastewaters, Water (Switzerland), 10, 10, 1-15, (2018).

[30] Ali, J., et al., Efficient, stable and selective adsorption of heavy metals by thiofunctionalized layered double hydroxide in diverse types of water, International Journal of Chemical Engineering, 332, September 2017, 387-397, (2018). 
[31] Sun, D. T., et al., Rapid, selective heavy metal removal from water by a metalorganic framework/polydopamine composite, ACS Central Science, 4, 3, 349356, (2018).

[32] Tizaoui, K., Benguella, B., ve Makhoukhi, B., "Selective adsorption of heavy metals $(\mathrm{Co} 2+, \mathrm{Ni} 2+$, and $\mathrm{Cr} 3+)$ from aqueous solutions onto natural marne clay, Desalination and Water Treatment, 142, 252-259, (2019).

[33] Kayacan, S., Kömür ve koklarla sulu çözeltilerden boyar maddelerin uzaklaştırılması, Yüksek Lisans Tezi, Ankara Üniversitesi, Ankara, (2007).

[34] Balc1, A., Astrazon kırmızısı ve astrazon mavisinin ticari aktif karbon üzerine adsorpsiyonu ve adsorpsiyon prosesinin optimizasyonu, Yüksek Lisans Tezi, Kilis 7 Aralık Üniversitesi, Kilis, (2018).

[35] Orbak, İ., Aktif karbon ile çevre kirletici bazı unsurların giderilmesi, Doktora Tezi, İstanbul Teknik Üniversitesi, İstanbul, (2009).

[36] Swenson, H. ve Stadie, N. P., Langmuir's theory of adsorption: A centennial review, Langmuir, 35, 16, 5409-5426, (2019).

[37] Langmuir, I., The constitution and fundamental properties of solids and liquids. Part I. Solids., Journal of the American Chemical Society, 38, 11, 2221-2295, (1916).

[38] Tümsek, F. ve Karabacakoğlu, B., Nikel ( II ) iyonlarının sulu çözeltiden granül aktif karbon üzerine adsorpsiyonu, Balıkesir Üniversitesi Fen Bilimleri Enstitüsü Dergisi, 14, 2, 1-6, (2012).

[39] Alkan, M. ve Dogan, M., Adsorption of copper (II) onto perlite, Journal of Colloid and Interface Science, 243, pp. 280-291, (2001).

[40] Wang, J., Ma, X., Fang, G., Pan, M., Ye, X. ve Wang, S., Preparation of iminodiacetic acid functionalized multi-walled carbon nanotubes and its application as sorbent for separation and preconcentration of heavy metal ions, Journal of Hazardous Materials, 186, 2-3, 1985-1992, (2011).

[41] Duran, A., Tuzen, M. ve Soylak, M., Preconcentration of some trace elements via using multiwalled carbon nanotubes as solid phase extraction adsorbent, Journal of Hazardous Materials, 169, 1-3, 466-471, (2009).

[42] Li, L., Huang, Y., Wang, Y. ve Wang, W., Hemimicelle capped functionalized carbon nanotubes-based nanosized solid-phase extraction of arsenic from environmental water samples, Analytica Chimica Acta, 631, 2, 182-188, (2015).

[43] Tuzen, M., Saygi, K. O. ve Soylak, M., Solid phase extraction of heavy metal ions in environmental samples on multiwalled carbon nanotubes, Journal of Hazardous Materials, 152, 2, 632-639, (2008).

[44] Vellaichamy, S. ve Palanivelu, K., Preconcentration and separation of copper , nickel and zinc in aqueous samples by flame atomic absorption spectrometry after column solid-phase extraction onto MWCNTs impregnated with D2EHPA-TOPO mixture, Journal of Hazardous Materials, 185, 2-3, 1131-1139, (2011).

[45] Zhao, X., Song, N. ve Jia, Q., Determination of $\mathrm{Cu}, \mathrm{Zn}, \mathrm{Mn}$, and $\mathrm{Pb}$ by microcolumn packed with multiwalled carbon nanotubes on-line coupled with flame atomic absorption spectrometry, Microchimica Acta, 166, 329-335, (2009).

[46] Çalışır, Ü., Organo-modifiye karbon nanotüplerin sentezi, karakterizasyonu ve bazı uygulama alanları, Doktora Tezi, Balıkesir Üniversitesi, Balıkesir, (2020).

[47] Çakir, Ü., Çiçek, B., Yildiz, Y.K., Alkan, M., Solvent effect upon 1on-pair extraction of different sodium dyes using some crown ethers, Journal of Inclusion Phenomena and Macrocyclic Chemistry, 34, 153-165, (1999).

[48] Çakir, Ü., Çiçek, B., Extraction-ability and -selectivity of tetra-aza-crown ethers 
for transition metal cations, Transition Metal Chemistry, 29, 263-268, (2004).

[49] Çiçek, B., Yıldız, A., Synthesis, Metal ion complexation and computational studies of thio oxocrown ethers, Molecules, 16, 8670-8683, (2011).

[50] Çiçek, B., Onbaşığlu, Z., Synthesis and characterization of 1,3,4-thiadiazole-2,5dithio crown ethers, Heterocyclic Communication, 22, 329-332, (2016).

[51] Çiçek, B., Çalışır, Ü., The investigation of complexation properties and hard-soft acid-base relationship between thiacrown ethers and metal ions, Letters in Organic Chemistry, 13, 572-577, (2016). 